\title{
Morphological and molecular identification of nasopharyngeal bot fly larvae infesting red deer (Cervus elaphus) in Austria
}

\author{
Natascha Leitner ${ }^{1} \cdot$ Laurin Schwarzmann $^{1} \cdot$ Carina Zittra $^{1} \cdot$ Nicola Palmieri $^{1}$. \\ Barbara Eigner $^{1}$ - Domenico Otranto ${ }^{2}$ - Walter Glawischnig ${ }^{3} \cdot$ Hans-Peter Fuehrer $^{1}$ (D)
}

Received: 30 May 2016 / Accepted: 13 July 2016/Published online: 5 August 2016

(C) The Author(s) 2016. This article is published with open access at Springerlink.com

\begin{abstract}
Nasopharyngeal myiases are caused by larvae of bot flies (Diptera: Oestridae), which have evolved a high specificity for their hosts. Bot flies $(n=916)$ were collected from 137 (57.6\%) out of 238 red deer (Cervus elaphus) hunted in Vorarlberg and Tyrol (Western Austria). After being stored in $75 \%$ ethanol, larvae were identified to species level and developmental stage using morphological and morphometric keys. Larvae were also molecularly characterized by polymerase chain reaction (PCR) amplification and partial sequencing of the mitochondrial cytochrome oxidase subunit I gene. Morphological and molecular analysis allowed identification of larvae as Cephenemyia auribarbis and Pharyngomyia picta. Genetic variations were also examined within the specimens collected in both geographical locations.
\end{abstract}

Keywords Cephenemyia auribarbis $\cdot$ Cervus elaphus . Cytochrome oxidase subunit I · Myiasis · Oestridae · Pharyngomyia picta

Hans-Peter Fuehrer

hans-peter.fuehrer@vetmeduni.ac.at

1 Institute of Parasitology, Department of Pathobiology, University of Veterinary Medicine Vienna, Veterinaerplatz 1, 1210 Vienna, Austria

2 Department of Veterinary Medicine, University of Bari, Str. Prov. Casamassima km3, 70010 Valenzano, Bari, Italy

3 Institute for Veterinary Disease Control Innsbruck, Austrian Agency for Health and Food Safety Ltd. (AGES), Technikerstrasse 70, 6020 Innsbruck, Austria

\section{Introduction}

To date, nasopharyngeal bot flies have been mostly studied in relationship to the economic damage they cause in animal husbandry (Otranto et al. 2003). Nasopharyngeal bot flies are known to be host specific and to cause obligatory myiasis in a wide range of animal species (Catts and Mullen 2002). Their development is holometabolic but (compared to other insects) is characterized by being larviparous (Catts and Mullen 2002; Colwell 2001). Soon after adult flies spray the first-stage larvae into the nostrils of the host, larvae migrate into the nasal and sinus cavities of the pharynx (Colwell 2001) therefore causing irritation, rhinitis, nasal discharge, purulent mucous exudates, and respiratory problems (Catts and Mullen 2002). Red deer (Cervus elaphus) is the main host for the nasopharyngeal bot fly species Cephenemyia auribarbis and Pharyngomyia picta (Colwell 2001; Vicente et al. 2004), both belonging to the subfamily Oestrinae (Catts and Mullen 2002; Colwell 2001). In addition, Cephenemyia stimulator, which is adapted to roe deer (Capreolus capreolus) (Colwell 2001), has on occasion been diagnosed in red deer (Király and Egri 2004, 2007). While the host spectrum of P. picta is broader, as this species can be detected regularly in red deer, sika deer (Cervus nippon), fallow deer (Dama dama), and roe deer, C. auribarbis is usually found in red deer and fallow deer only (Colwell 2001). Previous studies have shown that $C$. auribarbis occurs less frequently in red deer compared to P. picta (summarized in Vicente et al. 2004). Mixed infections of both $C$. auribarbis and P. picta in the same individual host were reported in Hungary (Sugár 1974) and in Spain (Ruíz Martinez and Palomares 1993), in 71.5 and $23.1 \%$ of examined red deer, respectively.

Molecular tools have shown to be successful and reliable for diagnostic and taxonomic studies of oestrid 
larvae (Otranto and Stevens 2002), and in particular, the cytochrome oxidase subunit I (coxI) mitochondrial gene has been used in several studies for the diagnosis and phylogeny of larvae within this taxon (Otranto and Stevens 2006).

Although the majority of bot fly infections occur in wildlife hosts, there is a lack of knowledge regarding these oestrids (Colwell et al. 2009). The aim of this study was not only to examine the species diversity of bot flies in Western Austrian red deer but also the use of morphometric and molecular tools for the analysis of variations (inter- and intra-species) within populations of these oestrids in a limited regional area.
Fig. 1 Distribution of larval species per host in Vorarlberg $(n=110$ red deer hosts in Vorarlberg; ESRI ArcGIS 10.1® was used for graphic design)

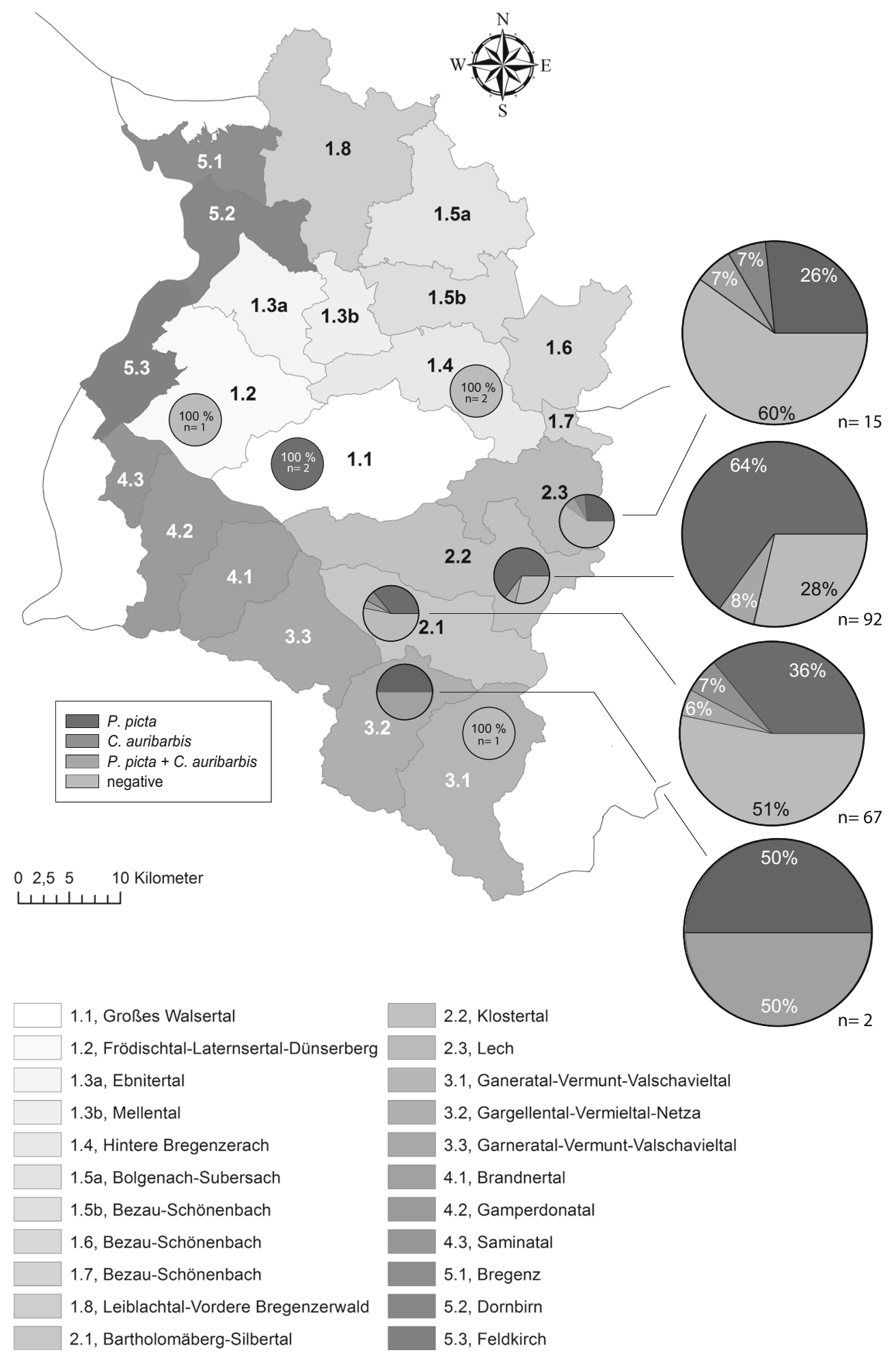




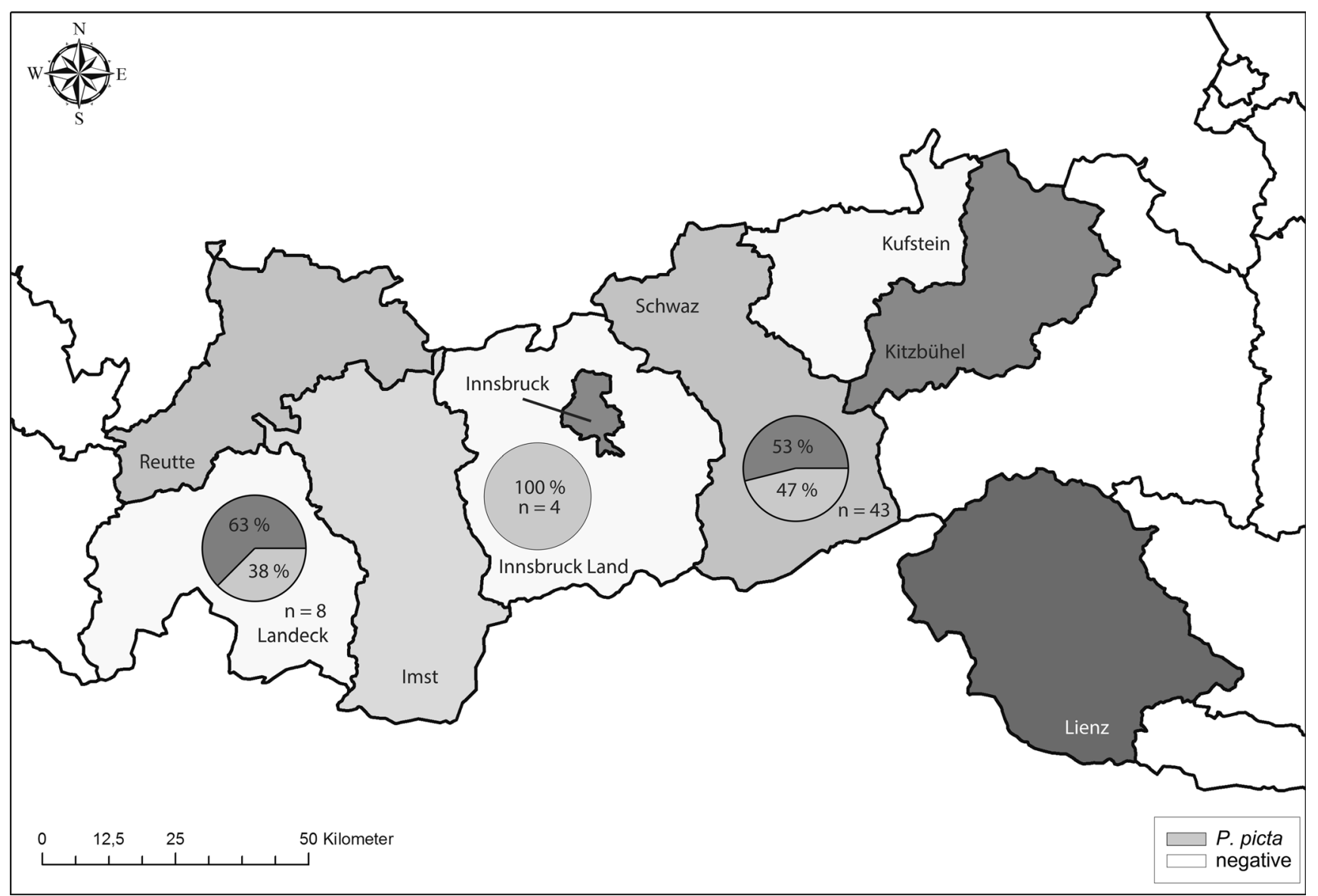

Fig. 2 Distribution of pharyngeal bot flies in red deer in Tyrol $\left(n=55\right.$ red deer hosts in Tyrol) per district (ESRI ArcGIS 10.1 ${ }^{\circledR}$ was used for graphic design)

\section{Materials and methods}

During the course of a regular shooting program, 238 red deer were shot in Western Austria (183 in Vorarlberg and 55 in Tyrol) from April to July 2014 and sent to the AGES Institute for Veterinary Disease Control in Innsbruck, Austria, immediately for necropsy. Sampling location, date, and sex of the red deer were collected whenever possible. Nasopharyngeal bot fly larvae were sampled at necropsy,

Table 1 Prevalence and mean number of larvae per host per sampled month (2014) and region

\begin{tabular}{cllll}
\hline & Positive hosts & Total hosts & Prevalence (\%) & Mean larvae \\
\hline Vorarlberg & & & & \\
April & 24 & 27 & 88.9 & 9.8 \\
May & 54 & 88 & 61.4 & 5.9 \\
June & 32 & 68 & 47.1 & 4.1 \\
Tyrol & & & & \\
May & 15 & 20 & 75.0 & 6.7 \\
June & 8 & 20 & 40.0 & 12.3 \\
July & 4 & 15 & 26.7 & 4.5 \\
\hline
\end{tabular}

stored in $75 \%$ ethanol at room temperature, and sent to the University of Veterinary Medicine Vienna, Austria, for further analysis. Bot fly larvae were cleaned from host nasal secretion using soft toothbrushes and microscopically identified to species level and developmental stage using identification keys by Zumpt (1965), Sugár (1974), and Draber-Monko (1975). Thirteen larval samples from ten red deer were sent to the Department of Veterinary Medicine, University of Bari, Italy, for blinded species identification.

A subset of the specified bot fly larvae were further analyzed by additional morphological tools and molecular techniques. Larvae $(n=48 ; C$. auribarbis $\mathrm{L} 3=11$ and $\mathrm{L} 2=3$ and P. picta $\mathrm{L} 3=30$ and $\mathrm{L} 2=4$ ) were measured with regard to

Table 2 Mean body width (mm) and body length ( $\mathrm{mm})$ per bot fly species and larval stage

\begin{tabular}{lll}
\hline Body width and length $(\mathrm{mm})$ & L2 & L3 \\
\hline P. picta body width & $5.368(\sigma=2.50)$ & $7.895(\sigma=0.56)$ \\
P. picta body length & $17.534(\sigma=5.49)$ & $24.939(\sigma=2.59)$ \\
C. auribarbis body width & $5.364(\sigma=0.56)$ & $7.489(\sigma=0.54)$ \\
C. auribarbis body length & $16.009(\sigma=1.75)$ & $29.391(\sigma=2.21)$
\end{tabular}


the following: body length, from the tip to the end of the larva; body width at the widest part of the larva; shape of posterior spiracular plates; and distance between the antennal lobes at the base of the antenna (Nikon SMZ 1270 and NIS Elements D 4.30.02-software, Nikon, Tokyo, Japan).

Fig. 3 Molecular phylogenetic analysis by maximum likelihood method. The evolutionary history was inferred by using the maximum likelihood method based on the general time reversible model (Nei and Kumar 2000). The tree with the highest $\log$ likelihood $(-1580.9403)$ is shown. The percentage of trees in which the associated taxa clustered together is shown next to the branches. Initial tree(s) for the heuristic search were obtained automatically by applying neighbor-joining and BioNJ algorithms to a matrix of pairwise distances estimated using the maximum composite likelihood (MCL) approach and then selecting the topology with superior $\log$ likelihood value. The tree is drawn to scale, with branch lengths measured in the number of substitutions per site. The analysis involved 46 nucleotide sequences. There were a total of 679 positions in the final dataset. Evolutionary analyses were conducted in MEGA6 (Tamura et al. 2013)
DNA was extracted from 44 larvae $(10$ C. auribarbis and 34 P. picta) using the DNeasy ${ }^{\mathrm{TM}}$ Blood and Tissue Kit (Qiagen, Hilden, Germany) according to the manufacturer's instructions. PCR amplifications were performed with dipteran-specific barcode primers (H15CuliCOIFw:5'AGCCATTTAATCGCGACAA-3';H15CuliCOIRv:5'-GGAT

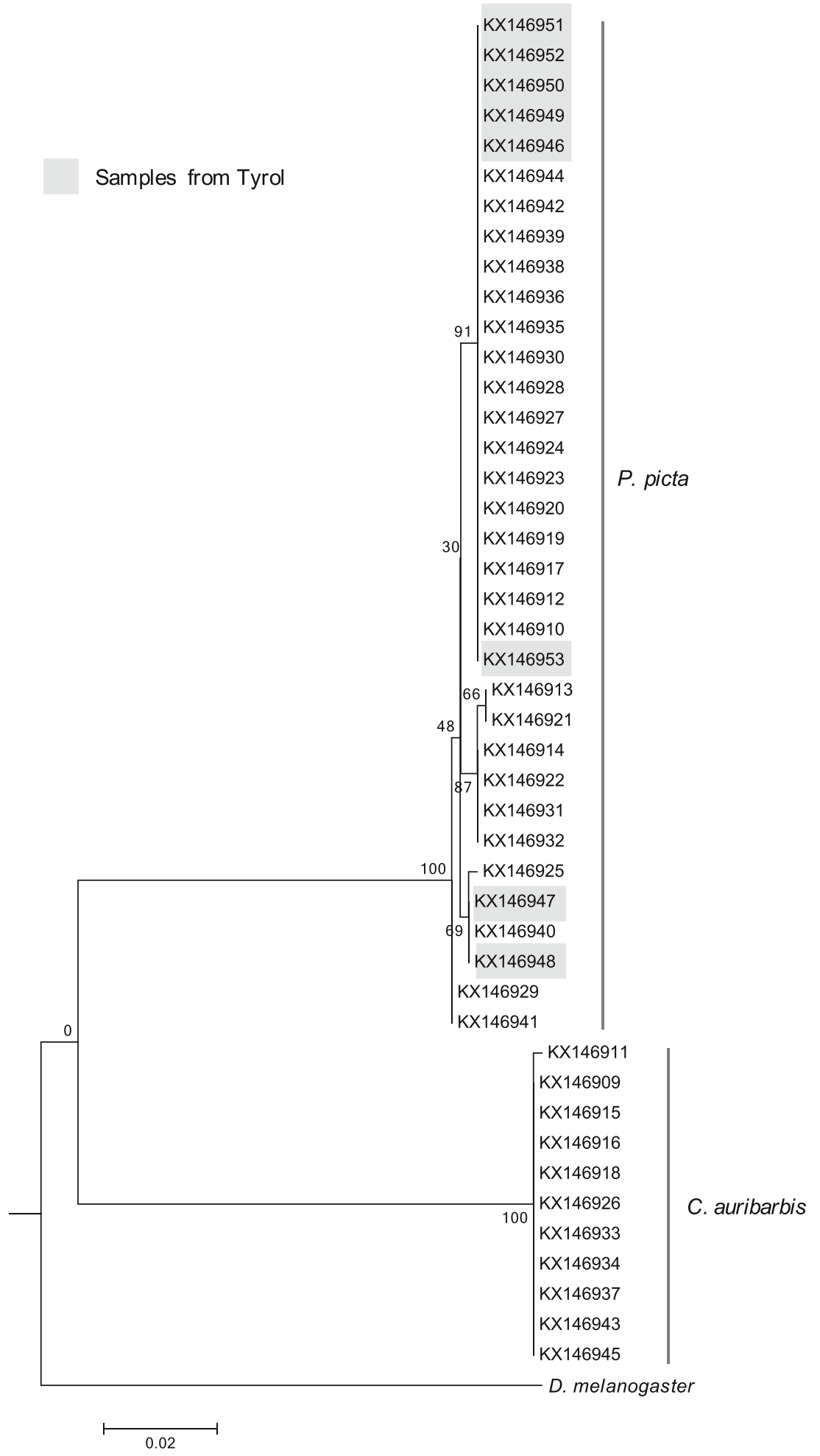


GTCCAAAAAATCAAAATAAATGTT-3') in a Mastercycler Gradient S (Eppendorf, Germany) under conditions reported previously (Zittra et al. 2016). Amplification products were subjected to agarose gel electrophoresis on $1.8 \%$ agarose gels at $120 \mathrm{~V}$ for $70 \mathrm{~min}$. Subsequently, gels were stained with Midori Green Advance (Biozym Scientific GmbH, Hess. Oldendorf, Germany), and PCR amplicons of approximately $730 \mathrm{bp}$ were visualized by UV light. DNA sequencing was performed at LGC GmbH (Berlin, Germany). All phylogenetic analyses were conducted with MEGA6 (Tamura et al. 2013), and sequences were aligned with ClustalW (Thompson et al. 1994) including Drosophila melanogaster as the out-group. The GTR model of sequence evolution with uniform rates was chosen by scanning 24 possible models and selecting the one with the lowest Bayesian information criterion. The tree was constructed by maximum likelihood using 1000 bootstrap replicates.

\section{Results and discussion}

Overall a total of 916 bot fly larvae - 49 were identified as C. auribarbis and 827 as P. picta-were retrieved in 137 out of 238 red deer (57.6\%; $95 \%$ CI, 51.2-63.7 \%; Figs. 1 and 2). For 40 larval specimens, the morphological identification was not possible due to their poor condition. P. picta was documented in 130 red deer (54.6\%; $95 \%$ CI, 48.3-60.8\%) whereas $C$. auribarbis was found in 19 red deer $(8 \%$; $95 \%$ CI, 5.2-12.1\%). Co-infections with both bot fly species were detected in 13 individual hosts $(5.5 \%$; $95 \% \mathrm{CI}, 3.2-$ $9.1 \%$ ). Both prevalence and distribution varied within the provinces sampled in Vorarlberg and Tyrol. C. auribarbis was only found in animals from Vorarlberg whereas $P$. picta was the prominent bot fly species in red deer in both regions (Vorarlberg, $56.3 \%$; Tyrol, 49.1\%). The prevalence of nasal bot fly in red deer is known to vary from $41.89 \%$ in central Spain (De la Fuente et al. 2000) to $85 \%$ in Spain (Bueno-de la Fuente et al. 1998), 90 \% in southern Spain (Ruíz Martinez and Palomares 1993), and 98.2 \% in Hungary (Sugár 1974). Our findings are in general agreement with these previous studies though the sampling season may affect the prevalence of bot flies in red deer and also the co-occurrence of both C. auribarbis and P. picta in the same host (cf. Vicente et al. 2004; Ruíz Martinez and Palomares 1993). Overall, P. picta was the dominant species found in this study, whereas C. auribarbis was rarely identified in infested animals in Vorarlberg and not in Tyrol. This may be related to the different developmental periods throughout the year (cf. Vicente et al. 2004; Ruíz Martinez and Palomares 1993). Concerning the seasonal dynamics in Vorarlberg, the number of larvae per host as well as the prevalence decreases throughout the sampled period from April to June (Table 1). Similar to the findings of Ruíz Martinez and Palomares (1993), no differences in the host preference between male and female infected hosts were observed in this study. The data conflict with previous observations by Vicente et al. (2004) and Bueno-de la Fuente et al. (1998) who recorded a higher prevalence in male hosts.

The retrieval of the majority of L3 and any L1 larvae might be associated with the sampling season (the percentages of larval stages which could be clearly identified were $P$. picta: $n_{\mathrm{L} 2}=9.1 \%, n_{\mathrm{L} 3}=90.9 \% ;$. auribarbis: $n_{\mathrm{L} 2}=8.7 \%$, $n_{\mathrm{L} 3}=91.3 \%$ ). Morphometric analysis of the bases of the antennal lobes allowed differentiation of $C$. auribarbis L3 (mean value $=0.187 \mathrm{~mm}, \sigma=0.08$ ) from $P$. picta L3 (mean value $=0.482 \mathrm{~mm}, \sigma=0.07)$. The mean body length of C. auribarbis L3 was $29.391 \mathrm{~mm}(\sigma=2.21)$, compared to $24.939 \mathrm{~mm}(\sigma=2.59)$ in . picta (Table 2). For the morphological analysis, the general shape (especially the posterior spiracles) of the larvae, but also body length, dorsal spine rows, and pigmentation allowed species differentiation (cf. Zumpt 1965; Sugár 1974; Draber-Monko 1975).

Nucleotide sequences of 44 bot fly larvae (10 C. auribarbis and $34 P$. picta) were analyzed within the barcode region of the cytochrome oxidase subunit I gene. C. auribarbis and $P$. picta could be separated clearly showing variations in 87 loci (GenBank ${ }^{\mathrm{TM}}$ : KX146909-KX146953). Furthermore intra- and inter-species variations were observed within the barcode region of $C$. auribarbis and P. picta (Fig. 3) therefore indicating that the selected target gene is effective for the species discrimination. However, further molecular-based studies are needed to monitor genetic variation within the populations of bot flies in Austria.

Acknowledgments Open access funding provided by University of Veterinary Medicine Vienna. Parts of this study are associated with the Austrian Barcode of Life Project (ABOL).

\section{Compliance with ethical standards}

Ethical approval All animals were killed in the course of the regular shooting program of the particular hunting area in consideration of the game law (Landesjagdgesetz) of Vorarlberg LGBI Nr. 32/1988 and Tyrol LGB1. Nr. 41/2004.

Open Access This article is distributed under the terms of the Creative Commons Attribution 4.0 International License (http://creativecommons.org/ licenses/by/4.0/), which permits unrestricted use, distribution, and reproduction in any medium, provided you give appropriate credit to the original author(s) and the source, provide a link to the Creative Commons license, and indicate if changes were made.

\section{References}

Bueno-de la Fuente MI, Moreno V, Peréz JM, Ruíz-Martínez I, Soriguer RC (1998) Oestrosis in red deer from Spain. J Wildlife Dis 34(4):820-824 
Catts EP, Mullen GR (2002) Myiasis (Muscoidea, Oestroidea). In: Mullen G, Durden L (eds) Medical and veterinary entomology. Elsevier Science Academic Press, San Diego, pp 317-348

Colwell DD (2001) Bot flies and warble flies (order Diptera: family Oestridae). In: Samuel WM, Pybus MJ, Kocan AA (eds) Parasitic diseases of wild mammals, 2nd edn. Manson Publishing, London, pp 46-71

Colwell DD, Otranto D, Stevens JR (2009) Oestrid flies: eradication and extinction versus biodiversity. Trends Parasitol 25(11):500-504

De la Fuente C, San Miguel JM, Santín M, Alunda JM, Dominguéz I, López A, Carballo M, Gonzáles A (2000) Pharyngeal bot flies in Cervus elaphus in central Spain: prevalence and population dynamics. J Parasitol 86(1):33-37

Draber-Monko A (1975) Morphologie einiger fliegenlarven der familie oestridae (Diptera). Ann Zool 32(10):239-247

Király I, Egri B (2004) A Tolna megyei őzállomány orrgaratbagócosfertőzöttségől [Nasopharyngeal bot infestation of roe deer population of Tolna county]. Magyar Állatorvosok Lapja 126:433-438 [In Hungarian]

Király I, Egri B (2007) Epidemiological characteristics of Cephenemyia stimulator (Clark, 1815) larval infestation in European roe deer (Capreolus capreolus) in Hungary. Acta Zool Acad Sci Hung 53(3):271-279

Nei M, Kumar S (2000) Molecular evolution and phylogenetics. Oxford University Press, New York

Otranto D, Stevens JR (2002) Molecular approaches to the study of myiasis-causing larvae. Int J Parasitol 32(11):1345-1360

Otranto D, Stevens JR (2006) Molecular phylogeny and identification. In: Colwell DD, Hall MJR, Scholl PJ (eds) The Oestrid flies—biology, host-parasite relationships, impact and management. Cabi Publishing, Cambridge, pp 51-66
Otranto D, Traversa D, Guida B, Tarsitano E, Fiorente P, Stevens JR (2003) Molecular characterization of the mitochondrial cytochrome oxidase I gene of oestridae species causing obligate myiasis. Med Vet Entomol 17(3):307-315

Ruíz Martinez I, Palomares F (1993) Occurrence and overlapping of pharyngeal bot flies Pharyngomyia picta and Cephenemyia auribarbis (Oestridae) in red deer of southern Spain. Vet Parasitol 47(1-2):119-127

Sugár L (1974) The occurrence of nasal throat bot flies (Oestridae) in wild ruminants in Hungary. Parasitologia Hungarica 7:181-189

Tamura K, Stecher G, Peterson D, Filipski A, Kumar S (2013) MEGA6: molecular evolutionary genetics analysis version 6.0. Mol Biol Evol 30:2725-2729

Thompson JD, Higgins DG, Gibson TJ (1994) CLUSTAL W: improving the sensitivity of progressive multiple sequence alignment through sequence weighting, position-specific gap penalties and weight matrix choice. Nucleic Acids Res 22(22):4673-4680

Vicente J, Fierro Y, Martínez M, Gortázar C (2004) Long-term epidemiology, effect on body condition and interspecific interactions of concomitant infection by nasopharyngeal bot fly larvae (Cephenemyia auribarbis and Pharyngomyia picta, Oestridae) in a population of Iberian red deer (Cervus elaphus hispanicus). Parasitology 129:349-361

Zittra C, Flechl E, Kothmayer M, Vitecek S, Rossiter H, Zechmeister FHP (2016) Ecological characterization and molecular differentiation of the Culex pipiens complex taxa and Culex torrentium in Eastern Austria. Parasit Vectors 9(1):197. doi:10.1186/s13071016-1495-4

Zumpt F (1965) Myiasis in man and animals in the old world. Butterworth, London, pp 141-153 